\title{
A Contingent Claims Approach to the Determinants of the Stock-Bond Return Relationship
}

Louisa Chen ${ }^{1}$ and Thanos Verousis*2

\begin{abstract}
This paper decomposes two effects on a firm's stock and bond returns - the effect of firm's future cash flow and the effect of business risk to study the relationship between the returns of stocks and bonds issued by the same firm. Based on the contingent claims option pricing theory, we employ firm-level data and an event study methodology, and generate hypotheses regarding the stock-bond return relationship. We show that, by controlling for firm's leverage, firm's future cash flow has a simultaneous positive effect on firm's stock and bond returns, whereas firm's business risk has a decoupling effect on stock and bond returns. In addition, we provide evidence for the "flight to quality" hypothesis at a firm-specific level. Our findings complement the literature of stock and bond correlation within a theoretical framework.
\end{abstract}

Keywords: stock-bond relationship; Contingent claims analysis; Option pricing theory; firm performance; business risk

JEL Classification: C01; G14; G32

\footnotetext{
${ }^{1}$ School of Business, Management, and Economics, University of Sussex, United Kingdom, email: L.X.Chen@sussex.ac.uk

$2 *$ Corresponding author. Newcastle University Business School, Newcastle University, Newcastle upon Tyne, United Kingdom. E-mail address: thanos.verousis@ncl.ac.uk
} 


\section{Introduction}

In this paper, we investigate the determinants of firms' stock-bond return relationship within the contingent claims analysis (henceforth, CCA) framework. The relationship between stock and bond returns has undergone extensive empirical investigations at both aggregate and firm level. At aggregate level, there is a consensus that the correlation of bonds and stock returns is state dependent and is affected by macroeconomic factors (see Barsky 1989; Cappiello et al. 2006 and Lee et al. 2011). At firm level, several studies report a time-varying correlation between stock and bond returns issued by the same firm (see Shane 1994; Hotchkiss and Ronen 2002; Kwan 1996; Alexander et al. 2000 and Bao and Hou 2013). Our study complements the latter literature by explaining why the correlation between these two sets of asset returns is time-varying using firm fundamentals from an explicit CCA perspective.

For this purpose, we re-visit the classic CCA, and use its theoretical underpinnings to infer the effects of a firm's future cash flow and business risk on the firm's stock-bond return relationship. CCA is a generalization of the option pricing theory pioneered by Black and Scholes (1973) and Merton (1973), that has been applied to a wide variety of contingent claims, such as corporate bonds and equities (see Merton 1974, Galai and Masulis, 1976 and Koussis and Martzoukos, 2012). In relation to our study, the CCA option pricing model suggests that holders of risky corporate bonds can be thought of as issuers of call options to the holders of a firm's equity, where the underlying asset is the market value of the firm; the holders of the firm's equity will therefore take the residual of the firm's total asset at maturity. Assuming firm value is irrelevant to firm's capital structure, Merton (1974) indicates that bond returns have a positive relationship with the return of firm assets and a negative relationship with changes in the volatility of firm assets. Galai and Masulis (1976) propose that stock and bond returns are positively related to the return of firm assets, whereas stock (bond) returns are negatively (positively) related to the volatility of firm assets. We therefore develop a set of hypotheses 
that conform to these theoretical predictions. Specifically, the return on a firm's total assets is expected to have the same impact on both stock and bond returns of that firm; whereas volatility or changes in the volatility of a firm's total assets leads to a divergence of stock and bond returns.

Exploring the stock-bond correlation persists as an interesting research topic for academics and practitioners. Within a firm's capital structure, it is believed that the prices of a firm's stocks and bonds should move together. However, a stock-versus-bond price divergence might exist and hence induce arbitrage opportunities. For instance, a company's bonds may trade in line with its total asset value, but its stock may trade at a higher price. In this situation, a riskless arbitrage strategy appears to exist when purchasing the bonds while selling the stock short (see Fridson and Jonsson 1997). In addition, the stock-versus-bond price divergence has an effect on the firm's financial decisions - at times when the firm needs to raise funds for new investments, the choice of equity financing or debt/bond financing is affected by the firm's stock and debt/bond price divergence.

At aggregate level, the negative correlation of stock and bond index returns since the mid-90s have generated significant academic inquiries regarding the nature and origins of that relationship (see Campbell and Taksler 2003 and Baele et al. 2010). It is clear that a reduction in the positive correlation of stock and bond returns could promote financial stability by creating more opportunities for risk diversification. Following this line of research, our study aims to explore the fundamental determinants of the stock-bond return relationship at firm level by employing a CCA perspective.

We use firm-level data and an event study methodology during the periods of two firmspecific events: trading statement announcements and financial year-end reports. Since these two types of events update firm fundamentals (i.e., firm's future cash flows and business risk) to the market, the periods around the events are suitable to detect the effects of return on firm's 
total assets and volatility on the stock-bond correlation. By controlling for firm leverage, we find that an increase in return on firm total assets has a simultaneous positive impact on both stock and bond returns; whereas an increase in volatility or a change in the volatility of firm total assets causes stock and bond returns to decouple. That is, when firm business risk increases, the value of the call options increases, benefiting stockholders at the expense of bondholders, and vice versa. The latter finding corresponds with the study of Campbell and Taksler (2003) in which firm-level equity volatility helps in explaining the increases in corporate bond yields since the late 1990s, a period during which US stock prices rose strongly in contrast to the coinciding poor corporate bond performance. However, the analysis in Campbell and Taksler (2003) is not strictly grounded in Merton's (1974) model in the sense that they only consider firm volatility in their empirical analysis. In addition, the use of equity return volatility as a proxy of firm volatility is not formulated as it is in Merton's model. Our findings are also close to Lee et al. (2011) where the income effect drives a positive correlation of stock and bond returns in the aggregate market, and the substitution effect induces a negative correlation of stock and bond returns. Whilst the empirical investigation in Lee et al. (2009) attempts to relate to Barsky's (1989) general equilibrium model where increased risk and reduced productivity growth lead to the "flight to quality" phenomenon, we provide a different (although complementary) firm-level investigation with a theoretical underpinning that supports the empirical evidence.

Our findings are also consistent with the broader empirical literature, e.g., in individual firm level, the information content of dividend hypothesis predicts that unexpected dividend changes move stock and bond returns together (see Handjinicolaou and Kalay 1984; and Dhillon and Johnson 1994), whereas the wealth redistribution hypothesis argues a negative stock and bond return co-movement (see Datta and Dhillon 1993 and Alexander et al. 2000). 
In aggregate level, the "flight to quality" hypothesis indicates that the periods of negative stockbond return correlations tend to coincide with stock market crashes (see Connolly et al. 2005).

Moreover, we find that firms' leverage strategy plays a role in the stock-bond relationship: a firm with a low rate of return along with a high leverage strategy causes stock returns to decrease but bond returns to increase; by contrast, a firm with a high rate of return along with a high leverage strategy causes stock returns to increase but bond returns to decrease. This finding conforms to Opler and Titman (1994), where lower stock returns of more leveraged firms in distressed industries are documented.

Compared to prior studies, our study is important for three reasons: first, we fill a void in the literature on the determinants of the stock-bond return relationship based on the theoretically rigorous and well-accepted CCA framework ${ }^{3}$ where firms' future cash flows and business risk are the key determinants of this relationship, thereby disentangling their impact on bond and stock returns. Secondly, the individual firm level investigation avoids the composition effect ${ }^{4}$ which might induce spurious interpretation of the stock-bond return correlation at the aggregate market level. Finally, we contribute further evidence for the "flight to quality" hypothesis at a firm-specific level. From a CCA perspective, our study also contributes to the recent literature that employs the predictions of the CCA to infer the effect of uncertainty on stock and bond returns and optimal capital structure decisions (see Doukas et al. 2014 and Koussis and Martzoukos 2012).

\footnotetext{
${ }^{3}$ The Merton contingent claims model was first adapted and applied commercially by KMV (now Moody's KMV) and is now firmly established as the theoretical basis for several applied models that are widely used in the investment industry to measure and evaluate credit risk for corporate firms, financial institutions, and sovereign debts (see KMV 1999; Gray et al. 2007; and Jobst and Gray 2013).

${ }^{4}$ A composition effect exists if corporate bonds are issued by different companies rather than those that dominate value-weighted equity indexes (see Campbell and Taksler 2003).
} 
The rest of the paper is organized as follows: Section 2 discusses the relevant literature on stock-bond correlation and develops the hypotheses. Section 3 provides a description of the data and methods and Section 4 reports and interprets the empirical results. Finally, Section 5 summarizes the findings.

\section{Literature review and hypotheses}

There is substantial literature with empirical evidence on the nature and the determinants of the stock-bond relationship at an aggregate or portfolio level, e.g., the relationship between government bonds and stocks or the relationship between stock indexes and corporate bonds. The early literature on the stock-bond relationship dates back to Keim and Stambaugh (1986) who reported a positive correlation between stock and bond returns. Kwan (1996) provides similar findings. Subsequent studies on the stock-bond correlation puzzle have shown that in periods of stock market uncertainty, investors prefer investing in bonds causing the "flight to quality" phenomenon (see Barsky 1989; and Connolly et al. 2005, 2007). Recently, several studies examine the dynamic correlation of bond and stock returns (see Baele et al. 2010; Norden and Weber 2009; and Yang et al. 2009). The consensus across these studies is that the correlation of stock and bond returns is state dependent and is affected by macroeconomic factors, such as real interest rates and inflation rates. With reference to Barsky's (1989) general equilibrium model, Lee et al. (2011) propose that it is the income effect that drives the positive correlation between stock and bond returns and the substitution effect that drives the negative correlation in the aggregate market.

At individual firm level, there are a number of empirical studies with mixed findings. Hotchkiss and Ronen (2002) use 55 high-yield bonds in the US market for 1995 and find positive correlations between bond returns and the issuing firm's stock returns (see also Shane 1994). Kwan (1996) demonstrates that firms' stock and bond returns are negatively and 
contemporaneously correlated in the long run and Alexander et al. (2000) show that the two asset returns move together in the long run but exhibit a negative relationship on the day of a corporate wealth-transferring event. ${ }^{5}$ Bao and Hou (2013) show how the maturity structure of the firm and the firm's credit risk affect the strength of the co-movement. However, to date, although certain patterns of the stock-bond return relationship are documented, the fundamentals that cause this time-varying relationship have yet to be investigated and addressed within the classic CCA framework.

In relation to our paper, two empirical hypotheses mirror the effects of future firm cash flow and business risk on the stock-bond return relationship. ${ }^{6}$ The information content of dividends hypothesis predicts that unexpected dividend changes will affect the market value of the firm, and consequently both stock and bond returns will move with the market value of the firm (see Handjinicolaou and Kalay 1984; and Dhillon and Johnson 1994). The wealth redistribution hypothesis, which stems from the conflict of interest between stockholders and bondholders, states that an increase in the stock price is accompanied by a decrease in the bond price, and vice versa. This can be the result of certain firm-specific events, such as dividend change announcements which might imply an increase in the variance of the firm's future cash flow (see Galai and Masulis 1976; Datta and Dhillon 1993 and Alexander et al. 2000).

Nevertheless, in spite of the large number of empirical studies that have sought to find correlation patterns and a smaller number of studies on the determinants of the relationship between stock and bond returns, the investigations are elusive with mixed findings. The CCA

\footnotetext{
${ }^{5}$ In Alexander et al. (2000), wealth-transferring events refer to the announcements of corporate events that suggest the possibility of a wealth transfer between stockholders and bondholders, e.g., senior debt issuance/redemption, adoption of a risky project, stock issuance/repurchase, changes in short-term liabilities and changes to dividend payments.

${ }^{6}$ See Handjinicolaou and Kalay (1984) for a general review and discussion.
} 
model traced back to Black and Scholes (1973) provides the theoretical foundation to construct the determinants of stock-bond correlation and thereby formulate our hypotheses. In their seminar work, Black and Scholes (1973) illustrate that the option pricing model can be used to evaluate corporate liabilities. Merton $(1973,1974)$ extends the Black-Scholes model to price corporate bonds, in which every security can be viewed as a contingent claim on the value of the underlying firm. Hence, the value of the security depends only on the risk-free interest rate ${ }^{7}$, the market value of the entire firm, and its volatility. Specifically, the price of a bond is an increasing function of the return of firm's assets but a decreasing function of the volatility of firm's assets. In the Merton's CCA framework, Galai and Masulis (1976) evaluate equities by combining the option pricing model and the capital asset pricing model. They show that the value of equity is an increasing function of the return of firm's assets and the volatility of firm's assets. These studies evaluate corporate bonds and stocks in continuous time. To fit in our study, we convert these relationships to discrete-time equations as follows.

$$
1 \geq \frac{\Delta S}{\Delta V} \geq 0, \frac{\Delta D}{\Delta V}=1-\frac{\Delta S}{\Delta V} \geq 0
$$

where $\Delta S$ is the stock return, $\Delta V$ is the return of firm's total assets, and $\Delta D$ is the bond/debt return. Expression (1) indicates that for a leveraged firm, the return of firm's total assets has two components - the stock return and the bond return. Both stock and bond returns are positively related to the return of firm's total assets. An intuitive statement is that firm's future cash flow has a positive influence on the claims of the firm's stock and bond issues. In the

\footnotetext{
${ }^{7}$ Since the empirical analysis in our study focuses on short-term stock and bond returns, we assume that interest rate is unchanged during the sample period.
} 
meantime, the stock-bond return relationship is also affected by volatility-specific factors. One of these is changes in the variance of firm's total assets,

$$
\frac{\Delta S}{\Delta \sigma^{2}}>0, \frac{\Delta D}{\Delta \sigma^{2}}=-\frac{\Delta S}{\Delta \sigma^{2}} \leq 0
$$

where $\sigma^{2}$ is the variance of $\Delta V$, and $\Delta \sigma^{2}$ is the change in $\sigma^{2}$. Expression (2) indicates that for a leveraged firm, the relationship between the stock return and the change in the variance of firm's total assets is positive; however, the relationship between the bond return and the change in the variance of firm's total assets is negative. Since $\Delta \sigma^{2}$ reflects firm's business risk (see Jones et al. 1984), an intuitive interpretation of expression (2) is that an increase in firm's business risk has a wealth transferring effect between stockholders and bondholders, contributing to a negative stock-bond return relationship. A second volatility-specific factor also affects the stock and bond return in an opposite way,

$$
\frac{\Delta S}{\sigma^{2}}<0, \frac{\Delta D}{\sigma^{2}}>0
$$

Expression (3) indicates that for a leveraged firm, the relationship between the stock return and the variance of firm's total assets is negative; however, the relationship between the bond return and the variance of firm's total assets is positive. Hence, an intuitive interpretation of expression (3) is that an increase in firm's business risk benefits stockholders at the expense of bondholders, contributing to a negative relationship between stock and bond returns. 
Based on the Expressions (1), (2) and (3), we generate two hypotheses regarding the determinants of the stock-bond return relationship, which directly reflect the anticipated effects of return of firm's total assets and its volatility ${ }^{8}$ on the stock and bond returns.

Hypothesis 1: Return of firm's total assets (i.e., firm's future cash flow) has a simultaneous positive impact on the firm's stock and bond returns, hence contributing to a positive correlation in stock and bond returns.

Hypothesis 2: Volatility of firm's total assets (i.e., firm's business risk) has a decoupling effect on the firm's stock and bond returns, driving the stock and bond returns move in opposite directions. Specifically:

Hypothesis 2a: A change in the volatility of firm's total assets has a positive impact on firm's stock returns but a negative impact on bond returns.

Hypothesis 2b: Volatility of firm's total assets has a negative impact on stock returns but a positive impact on bond returns.

\section{Data and methods}

To test Hypotheses 1 and 2, we conduct an event study analysis on the effects of return of firm's total assets and its volatility on stock and bond returns around two independent events: the announcement of trading statements ${ }^{9}$ (henceforth, TS) and the financial year-ends. We

\footnotetext{
${ }^{8}$ We use volatility instead of variance in the following analysis to avoid the smaller values of variance that might dilute the effect of business risk we try to capture.

${ }^{9}$ According to FSA rules, a firm listed on the London Stock Exchange (LSE) is required to inform the public if there is substantial change in the firm's financial, business or expected performance that is likely to affect the price of its listed securities
} 
begin by introducing the TS event study, followed by the financial year-end event study in this section.

For the TS event, we test Hypotheses 1 and 2a by examining the stock-bond return relationship in the period prior to the TS announcement day. This is because during the preannouncement period, the market has accumulated large amounts of uncertainty about a firm's future cash flow, until the arrival of TS resolves this uncertainty (see Bushee and Noe 2000). The pronounced changes in the market value of a firm's total assets and its volatility make the pre-announcement period suitable for our study (see Diamond and Verrecchia 1991 and the following Section 4).

Setting each firm's TS announcement day as event day $t=0$, we experiment with three event windows $(-30,-4),(-40,-4)$ and $(-50,-4)$. The chosen event windows are at least one month before the announcement in order to generate enough signals that can be captured by the market, and also to increase the sample size in the panel data regressions. Therefore, the analyses based on the three event windows also serve as a robust test to each other. In addition, to avoid the sharp changes of a firm's value on the announcement day causing a biased regression analysis, the examination event windows are up to 4 days ahead the TS announcement day. ${ }^{10}$

The original sample of TSs is from two sources: The Bank of England provides an electronic copy of negative TSs from 2000:1 to 2006:6. The other source of TSs is from the PI

\footnotetext{
${ }^{10}$ In the identification of the event window, we follow the approach discussed by Campbell et al. (1997). In Campbell et al. (1997) "Chapter 4. Event-study analysis" p.151 indicates that “...The period prior to or after the event may also be of interest and included separately in the analysis. For example, in the earnings-announcement case, the market may acquire information about the earnings prior to the actual announcement and one can investigate this possibility by examining pre-event returns.
} 
Navigator database from 2000:1 to 2011:10. Our dataset ends in 2011 as it covers a 12-year period. Further, we have no reason to believe that our results would alter if the database were extended to include more recent periods as the UK financial market has remained relatively unchanged in the post-financial crisis era.We use the following steps to select the final sample:

1) TSs are deleted if firms do not have common stocks and at least one tradable bond listed on the London Stock Exchange (henceforth, LSE), or if the data of daily returns on stocks and bonds are not available.

2) TSs are deleted if firms are in the banking and general finance sector. The unique capital structure of banks and financial firms makes it difficult to compare their financial returns to those of firms in other sectors.

3) The chosen bonds must meet the following criteria: a) be a fixed-rate, straight bond denominated in pounds sterling; b) cannot be convertible to equity or contain any equity feature such as a warrant; and c) must have six months of trading from its issuing day and a maturity time greater than one year. ${ }^{11}$

The final sample consists of 143 TS events and 115 financial year-end events. These events relate to 41 stocks and 47 bonds issued by 40 firms listed on the LSE over the period of 2000:9 to 2011:9. The remaining data are collected from DataStream. Clearly the key variable in our analysis is the return of firm's total assets. Following Jones et al. (1984), we estimate the market value of the firm as the sum of the market value of equity and the estimated market value of total liabilities, where the market value of total liabilities is estimated by assuming that the market-to-book ratio of the selected long-term tradable bond is the same for all other

\footnotetext{
${ }^{11}$ Goldstein and Hotchkiss (2007) show that bonds in the first 3 to 6 months of trading can display unusual liquidity. Bonds very close to maturity are less sensitive to firm-specific information.
} 
tradable and non-tradable debts (i.e., total liabilities ${ }^{12}$ ). The logarithmic returns on the firm value $(R V)$ are calculated and, the volatility of $R V$ is determined over a 5-day rolling window. 13 The change in the volatility of $R V\left(D_{-} \operatorname{Vol}(R V)\right)$ is calculated as the logarithmic change of the volatility of $R V$.

We use a number of control variables. The Capital Asset Pricing Model (CAPM) predicts that market portfolio returns determine security returns. If a firm's market value increases when the market goes up, we should still expect a positive correlation in stock and bond returns. In addition, a high volatility in the return of a firm's total assets does not necessarily cause a negative correlation of stock and bond returns. If systematic volatility rises, so will the risk premium, which can drive up both stock and bond returns. Therefore, we include the FTSE100 market index returns (RM) and the volatility of the market index returns $(\operatorname{Vol}(\mathrm{RM}))$ to control for these two effects. ${ }^{14}$ In the option pricing model, the firm is passive, and its leverage is assumed to be fixed. Leverage measures the level of indebtedness of the

\footnotetext{
${ }^{12}$ The total liabilities are reported in the firm's next financial report released after the current TS announcement. For most of the TS announcements in the sample, the time gap from the previous year-end to the current TS announcement day is much greater than those after the current TS announcement; hence, we use the total liabilities reported in the post TS announcement period as an appropriate scaling factor in the measurement of firm asset values.

${ }^{13}$ Since we do not know the investment horizons of investors in the stock and bond markets, the setting of the event window used to compute volatility is arbitrary. The 5-day window is used to capture the well-documented weekend effect in stock markets (see Keim and Stambaugh 1984).

${ }^{14}$ In the literature, the CAPM market index returns is overwhelmingly a significant risk factor for asset returns (see Chen et al. 1986). Although there are other risk factors that have been documented to explain stock and bond returns in different periods and markets in the context of Asset Pricing Theory, e.g., macroeconomic variables, firm size, the book-to-market ratio, the term spread and the default spread (see Brennan et al., 2004; Lustig et al., 2013 and Koijen et al., 2012), we focus our analysis on the key determinants of stock and bond returns (and the returns relationship) with a decent scope regarding the degree of freedom in the regressions.
} 
firm. In practice, a firm might adjust its leverage as new information is revealed. For example, a firm can choose to retire some of its debts when earnings are high. Alternatively, the firm can be forced to issue more debt when its earnings become more volatile. The classic Modigliani and Miller (1958) capital structure theory indicates that the stock return of a levered firm is equivalent to the stock return of an unlevered firm plus a financial risk premium. Therefore, leverage induces a transfer of financial risk from bondholders to stockholders, resulting in an increase in stock returns but a decrease in bond returns. We control for this effect by including the leverage of the firm (Lev1) in the regression models. We implement the first set of hypothesis tests using the following panel data regression model: ${ }^{15}$

$$
\begin{gathered}
R_{i t}=\beta_{0}+\beta_{1} R V_{i t}+\beta_{2} D_{-} \operatorname{Vol}(R V)_{i t}+\beta_{3} R M_{i t}+\beta_{4} \operatorname{Vol}(R M)_{i t}+\beta_{5} L e v 1_{i t} \\
+\epsilon_{i t}
\end{gathered}
$$

where $R_{i t}$ refers to the natural logarithm returns of stocks $\left(R S_{i t}\right)$ or bond $\left(R B_{i t}\right)$, calculated at time $t$ and issued by firm $i ; R M_{i t}$ refers to logarithmic returns of the market index and $\operatorname{Vol}(R M)_{i t}$ refers to the volatility of $R M$ over an event window $(\mathrm{t}-5, \mathrm{t}) ; \operatorname{Lev} 1_{i t}$ is the natural

\footnotetext{
${ }^{15}$ We do not consider the impact of the 2007 - 2008 global financial crisis in the analysis for the following reasons. First, we have excluded TS announcements issued by firms that are in the banking and general finance sector (see Section 3), which is a major sector hit by the financial crisis. The lesser setbacks caused by the financial crisis and faced by non-financial firms are also shown in our TS announcements sample, in which the frequency of TS announcements in 2007 and 2008 is $12.17 \%$ and $6.09 \%$, respectively. With reference to the average yearly frequency of TS announcements of $8.33 \%$ from 2000 to 2011, the frequency of TS announcements during the financial crisis period of 2007 - 2008 does not look particularly high. Second, we attempt to focus our analysis on the key determinants of stock and bond returns (and their relationship) aside from other risk factors. Third, given the fact that we estimate event windows, we are not able to add dummy variables to test the effect of the financial crisis.
} 
logarithm of the ratio of market-value-of-total-debts to market-value-of-equity of the firm, where the market-value-of-total-debts is estimated as the interaction of total-debts and the market-to-book ratio of a long-term tradable bond of the firm; Other variables are defined as above. Finally, when $R B$ is the dependent variable, we also include a vector of lagged variables $\beta(L .)^{\prime}$ of $R V, D_{-} \operatorname{Vol}(R V), R M, \operatorname{Vol}(R M)$ and $\operatorname{Lev} 1$, that are used as control variables. ${ }^{16}$ All variables in Equation (4) are expressed in percentages.

[INSERT Table 1 here]

[INSERT Table 2 here]

Table 1 reports the summary statistics of variables involved in Equation (4) and their pair-wise correlations in the event window $(-30,-4)$. It is noteworthy that in Panel A of Table 1 , the average change in volatility of firm's total assets $\left(D_{-} \operatorname{Vol}(R V)\right)$ is 0.26 . This means that, on average, the volatility of firm's total assets is increasing. As the TS announcement day approaches, the market is accumulating more uncertainty on firm's future cash flow. Alternatively, Table 2 shows that the average $D_{-} \operatorname{Vol}(R V)$ is $0.26,0.08$ and 0.09 in the three event windows $(-30,-4),(-40,-4)$ and $(-50,-4)$ respectively, that also demonstrates an increasing trend of the changes in volatility of firm's total assets when the event window approaches the TS announcement day. This confirms our conjecture at the beginning of this section that the market accumulates uncertainty about the firm's future cash flow prior to the arrival of information in the public domain.

\footnotetext{
16 The Wooldridge test on serial correlation on Equation (4) with dependent variable of $R S_{i t}$ cannot reject the null hypothesis of no first-order autocorrelation, but the test rejects the null hypothesis on Equation (4) with dependent variable of $R B_{i t}$ without the lagged variables $\beta(L$.$) . Therefore, the lagged variables \beta(L$.$) are added in Equation$ (4) to overcome the serial correlation embedded in the initial model.
} 
The correlation matrix in Panel B of Table 1 shows that the return of firm's total assets $(R V)$ is positively correlated to the firm's stock and bond returns, but the change in the volatility of firm's total assets $\left(D_{-} \operatorname{Vol}(R V)\right)$ has an opposite correlation with stock and bond returns: $D_{-} \operatorname{Vol}(R V)$ is positively correlated to stock returns, but negatively correlated to bond returns. This is consistent with Hypotheses 1 and 2a. In the following section we will show that, through a panel data regression analysis, the return of firm's total assets and the change in the volatility of firm's total assets have a concurrent opposite impact on firm's stock and bond returns. In this respect, Panel B of Table 1 provides the first set of evidence to support our contention that the correlation of stock and bond returns is determined by the firm's future cash flow and business risk as implied by the CCA model. Moreover, the market index return is positively correlated to stock returns but negatively correlated to bond returns, which signals the "flight to quality" phenomenon. Again, the regression analysis in the following section sheds more light on this subject.

The second event study on the determinants of stock-bond return relationship is a crosssectional analysis during the firms' financial year-end dates, ${ }^{17}$ which aims to test Hypotheses 1 and $2 \mathrm{~b}$. We use two financial indicators as proxies for the return of firm's total assets and the volatility of firm's total assets - the earnings ratio (i.e. return-on-assets) and the leverage ratio (i.e. debt-to-equity). The earnings ratio is an indicator of the firm's profitability, that is to say, measures how good the management performance has been in using assets to generate earnings.

\footnotetext{
${ }^{17}$ In the UK, listed firms usually release annual financial reports to the market two months after the financial yearend. See Acker et al. (2002). Due to the problem that we cannot obtain a reasonable sample of the annual financial report release days, we presume that firms' financial information leaks to the market after the financial year-end day, such as through stock analysts, hence influencing the firm's stock and bond prices. Therefore, the financial year-end day event is employed in the current study. In our study, we only include market portfolio-related risk factors in Equations (1) and (2).
} 
The leverage ratio measures the level of indebtedness of a firm. Bradley et al. (1984) find that firm leverage ratio is negatively related to the volatility of firm earnings if the costs of financial distress are non-trivial. Hence, leverage can be a proxy for the volatility of firm's total assets. We test Hypotheses 1 and $2 \mathrm{~b}$ using the cross-sectional model as follows,

$$
R_{i}^{t}=\gamma_{0}+\gamma_{1} R O A_{i}+\gamma_{2} \operatorname{Lev} 2_{i}+\gamma_{3} R M_{i}+\gamma_{4} \operatorname{Vol}(R M)_{i}+z_{i}
$$

where $t$ refers to the first trading day after the financial report announcement day ${ }^{18} ; R O A$ refers to return-on-assets and Lev2 refers to the ratio of total-debts-to-total-equity. Both figures are reported in the annual financial reports. We include $R M$ and $\operatorname{Vol}(R M)$ as control variables for the reasons explained above. Since the stock and bond returns in the cross-sectional models are only one day after the financial year-end day, we assume that firms' leverage levels are unchanged. All variables in Equation (5) are expressed in percentages.

[INSERT Table 3 here]

Table 3 presents the summary statistics and the correlation matrix of the variables in Equation (5). The correlations of firm return-on-assets with stock and bond returns, and the correlations of the volatility of firm earnings (proxied by Lev2) with stock and bond returns provide the first set of evidence for Hypotheses 1 and 2b. Specifically, whereas firm return-on-

\footnotetext{
${ }^{18}$ We use the data on the first trading day after the financial year-end day to capture the price effects of the annual financial report announcements, as some of those reports are released after the stock market closes on the announcement day.
} 
assets is positively correlated to both stock and bond returns, the volatility of the firm earnings is positively related to the firm's stock return but negatively related to the firm's bond return. Furthermore, the market index return is positively correlated to stock return but negatively correlated to bond return, giving a first sign of the "flight to quality" hypothesis. The crosssectional regression analysis in the following section will elaborate on the hypothesis tests.

\section{Analysis}

In this section, we present and discuss the regression results of Equations (4) and (5). The regression of Equation (4) is to test Hypotheses 1 and 2a, where the panel data analysis across firms and event days in the pre-TS announcement period allows us to examine whether the return of firm's total assets and the changes of the volatility of firm's total assets have different impact on the firm's stock and bond returns simultaneously. We focus our analysis in the one-month event window $(-30,-4)$. For robustness, the analysis using longer event windows $(-40,-4)$ and $(-50,-4)$ is also presented. The regression of Equation (5) is to test Hypotheses 1 and $2 \mathrm{~b}$, where the cross-sectional analysis based on the day immediately after firms' financial year-end can demonstrate whether the return of firm's total assets (proxied by the earnings ratio) and its volatility (proxied by the debt-to-equity ratio) have a different impact on firm's current stock and bond returns.

Before we present the regression results, we show the one-sided t-test on the change in the volatility of firm's total assets $\left(D_{-} \operatorname{Vol}(R V)\right)$ between the pre-announcement period $(-30,-$ 4) and the corresponding post-announcement period $(4,30) . \quad D_{-} \operatorname{Vol}(R V)$ in the preannouncement period is 0.26 , and significantly higher than the post-announcement period at the $1 \%$ significance level. This implies that $D_{-} \operatorname{Vol}(R V)$ declines after the TS announcement day, confirming our assumption that the pre-announcement period is suitable in the current analysis. 
[INSERT Table 4 here]

We conduct the Hausman test for the stock return and the bond return regressions of Equation (4). The results suggest the use of a fixed effects model for both of the asset return regressions. Table 4 reports the estimation results using the fixed effects model. According to Hypothesis 1, we expect that the coefficients of the return of a firm's total assets (RV) to be positive for both sets of regressions. Also, according to Hypothesis 2a, we expect a positive coefficient of the change in the volatility of firm's total assets (D_Vol(RV) for stocks, and a negative one for bonds.

In the event window $(-30,-4)$, the coefficients of the return of firm's total assets $(R V)$ to stock returns $(R S)$ and bond returns $(R B)$ are 1.25 and 0.81 , respectively. Both coefficients are highly significant at the $1 \%$ significance level. This is consistent with Hypothesis 1 . That is, the return of firm's total assets causes a positive correlation of stock and bond returns. In particular, stockholders benefit more from an increase in the return of firm's assets because the coefficient of the return of firm's assets for stocks is higher than bonds. This is consistent with Handjinicolaou and Kalay (1984) in which the gains associated with positive information are captured by the stockholders whilst losses are shared with the bondholders. The coefficients of the change in the volatility of firm's total assets $\left(D_{-} \operatorname{Vol}(R V)\right.$ to stock and bond returns are significant at the $1 \%$ level with opposite signs, demonstrating that the change in the volatility of firm's total assets induces stock and bond returns to decouple and to move in opposite ways; hence, Hypothesis $2 \mathrm{a}$ is supported. These results reinforce our earlier findings as shown in Table 1, where $R V$ is positively related to $R S$ and $R B$ but $D_{-} \operatorname{Vol}(R V)$ has opposite correlations with the two asset returns. Putting in a more intuitive expression, high expectation on firm's future cash flow benefits both the firm's stockholders and bondholders, as has also been 
documented by Handjinicolaou and Kalay (1984) and Dhillon and Johnson (1994). However, changes in firm's business risk cause a wealth redistribution effect between stockholders and bondholders (see also Datta and Dhillon, 1993 and Alexander et al., 2000).

Amongst the control variables, the coefficients of market index returns $(R M)$ to stock and bond returns are 0.21 and -0.01 at the $1 \%$ significance level, respectively. This result lends evidence to the "flight to quality" hypothesis - when the stock market goes down, investors look for relatively safe investments and switch their holdings from stocks to bonds, and vice versa (see Barksy 1989 and Briere et al. 2012). The coefficients of leverage (Lev1) to stock and bond returns are -0.02 and 0.49 at the $1 \%$ significance level, respectively. At first glance, this contradicts the expected result that the coefficient should be positive to stock returns but negative to bond returns. One explanation is to look at the relationship between leverage and returns on firm's total assets. Panel B of Table 1 shows that the correlations between Lev1 and $R V$, and between $L e v 1$ and $D_{-} \operatorname{Vol}(R V)$ are negative in the event window $(-30,-4)$. This implies that firms strategically raise the leverage level when returns of firm's total assets and changes in volatility are low. Without a backing of good and stable firm performance, high leverage can cause high default risk and hence a high risk premium of bond returns; stock returns simultaneously decrease when risk transfers from stockholders to bondholders. This finding conforms to Opler and Titman (1994) whose study finds that the stock returns of more leveraged firms in distressed industries are substantially lower than those of their less leveraged rivals.

Next, to ensure that the documented results are not driven by a specific event window, we further estimate Equation (4) in the longer event windows $(-40,-4)$ and $(-50,-4)$. As seen from Table 4, the estimation results in the event windows $(-40,-4)$ and $(-50,-4)$ are mutually consistent to those in the event window $(-30,-4)$, except that the coefficient of $D_{-} \operatorname{Vol}(R V)$ and $R M$ to bond returns is insignificant in the longer event windows $(-40,-4)$ and $(-50,-4)$. One 
possible explanation is that $D_{-} \operatorname{Vol}(R V)$ becomes smaller in longer time periods before the TS announcement (see Table 1); hence, its impact on bond returns becomes less pronounced.

Turning to the analysis regarding firms' financial year-end events, Table 5 presents the estimation results of the cross-sectional regressions of Equation (5). The estimation is by OLS and the t-statistics are computed using the Huber-White robust standard errors to overcome a minor heteroscedasticity in the regressions.

\section{[INSERT Table 5 here]}

In line with Hypothesis 1, we anticipate that the coefficients of the return-on-assets $(R O A)$ will be positive for both stock and bond regressions. Also, in line with Hypothesis $2 \mathrm{~b}$, we expect a positive coefficient of the debt-to-equity ratio (Lev2) for stocks and a negative one for bonds.

The results show that the coefficient of return-on-assets $(R O A)$ to stock return is 0.01 and insignificant; the coefficient of return-on-assets to bond return is 0.01 at the $1 \%$ significance level. Although the estimated coefficient of $R O A$ to stock return is statistically insignificant with $\mathrm{p}$-value of 0.30 , the positive sign of the coefficient provides some evidence to Hypothesis 1: an increase in earnings causes a firm's stock and bond returns to increase together. The coefficients of the debt-to-equity ratio (Lev2) to stock returns is positive and to bond returns is negative, at the $1 \%$ and $10 \%$ significance level, respectively. We interpret the estimates in two aspects: firstly, Lev2 is an inverse proxy of the volatility on firm earnings as described in section 3. Hence, the fact that the estimated coefficient of Lev2 is positive for stock returns but negative for bond returns implies that increase in the volatility on firm earnings causes stock returns to decrease but bond returns to increase. Secondly, contrary to the negative relationship between firm leverage (Lev1) and the return of firm's total assets 
$(R V)$ in Equation (4), the relationship of Lev2 and $R O A$ in firms' financial year-ends (see Table 3) is positive. This result in fact reconciles the finding in Equation (4) that a high leverage level is backed by the high earnings of the firm; default risk therefore is relatively low, resulting in low bond returns but high stock returns. Likewise, the results of Table 5 verify our earlier findings shown in Table 3, where $R O A$ has positive relationships with $R S$ and $R B$ but Lev2 demonstrates opposite relationships with the two asset returns.

Furthermore, the coefficient of the market index return $(R M)$ is positive to stock return but negative to bond return at the $1 \%$ significance level. This is analogous to the estimates in Equation (4) that the divergence of stock and bond returns is related to the aggregate stock market performance. While individual stock returns go up with the stock market index return, the returns of the bonds issued by the same firm go down with the stock market index return. This confirms the evidence of "flight to quality" we report in the estimates of Equation (4).

In summary, the body of evidence presented so far appears consistent with Hypotheses 1 and 2. By controlling for the firm's leverage level, the stock market index return and its volatility, the correlation between firm's stock and bond returns is determined by firm's future cash flow (i.e., return of firm's total assets) and business risk (i.e., volatility or a change in the volatility of firm's total assets). While firm's future cash flow causes the firm's stock and bond returns to move together, firm's business risk dichotomizes the firm's stock return from its bond returns and moves these two asset returns in opposite directions. This finding tallies with the predictions of the CCA models. Eventually, the actual correlation between stock and bond returns depends on which effect is more dominating, the effect of firm's future cash flow or the effect of firm's business risk. In addition, firm's leverage level also plays an important role in the stock-bond return relationship. Depending on the firm's leverage strategy, a firm with poor performance but high leverage will have low stock returns but high bond returns; a firm with good performance and high leverage will have high stock returns but low bond returns. 


\section{Conclusion}

This paper aims to investigate the determinants of the stock-bond return relationship within the classic CCA framework. An innovation of our paper is that the predictions made regarding the effects of firm's future cash flow (i.e., return of firm's total assets) and business risk (i.e., volatility or a change in the volatility of firm's total assets) on the firm's stock-bond return relationship are derived from the CCA option pricing theory. Our hypotheses have strong theoretical justifications in the sense that the commonality and difference between stock and bond returns are endogenously rooted in the fundamental value of the firm and its volatility.

We use firm-level data and an event study methodology for the periods around two firm-specific events: trading statement announcements and financial year-end reports. The regression analyses in both event periods show that firm's future cash flow has a simultaneous positive impact on firm's stock and bond returns, whereas firm's business risk has an opposite impact on firm's stock and bond returns at the same time. Moreover, we find evidence of the "flight to quality" hypothesis - individual corporate bond returns go down while the stock market index return goes up. In addition, leverage plays a role in firm's stock-bond return correlation - low expected future cash flow accompanying high leverage has a negative impact on stock returns but a positive impact on bond returns, and it is the other way around when low expected future cash flow accompanies low leverage.

Certainly, the actual correlation between the two types of asset returns is determined by the relative importance of the firm's future cash flow effect and the business risk effect. If the firm's future cash flow effect is more dominating, we are likely to observe a positive correlation. Otherwise, we will observe a negative correlation. How to measure which effect dominates the other is a question for future research. Equally, assessing the role of liquidity in determining bond returns is an important issue that requires future research. 


\section{References}

Acker, D., J. Horton, and I. Tonks. 2002. “Accounting Standards and Analysts Forecasts: The Impact of FRS3 on Analysts' Ability to Forecast EPS.” Journal of Accounting and Public Policy 21(3): 193-217.

Alexander, G. J., K. A. Edwards, and M. G. Ferri. 2000. “What Does Nasdaq's High-yield Bond Market Reveal About Bondholder-stockholder Conflicts?” Financial Management (US) 29(1): 23-39.

Baele, L., G. Bekaert and K. Inghelbrecht. 2010. "The Determinants of Stock and Bond Return Comovements." Review of Financial Studies 23 (6): 2374-2428.

Bao, J. and K. Hou. 2013. "Comovement of Corporate Bonds and Equities." Fisher College of Business Working Paper No. 2013-03-11.

Barsky, R.B. 1989. "Why Don't the Prices of Stocks and Bonds Move Together?" The American Economic Review 79(5): 1132-1145.

Black, F. and M. Scholes. 1973. "The Pricing of Options and Corporate Liabilities.” Journal of Political Economy 81(3): 637-654.

Bradley, M., G. A. Jarrell and E. H. Kim. 1984. "On the Existence of an Optimal Capital Structure: Theory and Evidence.” Journal of Finance 39(3): 857-878.

Brennan, M.J., A.W. Wang and Y. Xia. 2004. "Estimation and Test of a Simple Model of Intertemporal Capital Asset Pricing.” The Journal of Finance 59(4): 1743-1775.

Briere, M., A. Chapelle and A. Szafarz. 2012. "No Contagion, Only Globalization and Flight to Quality." Journal of International Money and Finance 31(6): 1729-1744.

Bushee, B. J. and C. F. Noe. 2000. "Corporate Disclosure Practices, Institutional Investors, and Stock Return Volatility.” Journal of Accounting Research 38(3): 171-202.

Campbell, J.Y., A.W. Lo and A.C. Mackinlay. 1997. "The Econometrics of Financial Markets.” Princeton, NJ: Princeton University Press. 
Campbell. J.Y. and G.B. Taksler. 2003. "Equity Volatility and Corporate Bond Yields." The Journal of Finance 58(6): 2321-2350.

Cappiello, L., R.F. Engle and K. Sheppard. 2006. "Asymmetric Dynamics in the Correlations of Global Equity and Bond Returns.” Journal of Financial Econometrics 4(4): 537-572.

Chen, N. F., R. Roll and S. A. Ross. 1986. "Economic Forces and the Stock Market." Journal of Business 59(3): 383-403.

Connolly, R., C. Stivers and L., Sun. 2005. "Stock Market Uncertainty and the Stock-Bond Return Relation.” Journal of Financial and Quantitative Analysis 40(1): 161-193.

Connolly R., C. Stivers and L. Sun. 2007. "Commonality in the Time variation of Stock-Bond and Stock-Stock Return Comovements.” Journal of Financial Markets 10(2): 192-218

Datta, S. and U. S. Dhillon. 1993. "Bond and Stock Market Response to Unexpected Earnings Announcements.” Journal of Financial and Quantitative Analysis 28(4): 565-577.

Dhillon, U. S. and H. Johnson. 1994. "The Effect of Dividend Changes on Stock and Bond Prices." The Journal of Finance 49(1): 281-289.

Diamond, D. W. and R. E. Verrecchia. 1991. "Disclosure, Liquidity, and the Cost of Capital." Journal of Finance 46(4): 1325-1359.

Doukas, J., H. Gonen and A. Plantinga. (2014). "Private Acquisition Gains: A contingent Claims Explanation.” The European Journal of Finance 20 (12): 1090-1113.

Fridson, M.S. and J. G. Jónsson. 1997. “Contingent Claims Analysis.” Journal of Portfolio Management 23(2): 30-43

Galai, D. and R. W. Masulis. 1976. "The Option Pricing Model and the Risk Factor of Stock." Journal of Financial Economics 3(1): 53-81.

Goldstein, M.A. and E. S. Hotchkiss. 2007. "Dealer Behavior and the Trading of Newly Issued Corporate Bonds.” AFA 2009 San Francisco Meetings Paper. 
Gray, D. F., R.C. Merton and Z. Bodie. 2007. "Contingent Claims Approach to Measuring and Managing Sovereign Credit Risk.” Journal of Investment Management 5(4): 5-28.

Handjinicolaou, G. and A. Kalay. 1984. "Wealth Redistributions or Changes in Firm Value: An Analysis of Returns to Bondholders and Stockholders around dividend Announcements." Journal of Financial Economics 13(): 35-63.

Hotchkiss, E. S. and T. Ronen. 2002. "The Informational Efficiency of the Corporate Bond Market: An Intraday Analysis.” The Review of Financial Studies 15(5): 1325-1354.

Jobst, A. A. and D. F. Gray. 2013. "Systemic Contingent Claims Analysis - Estimating Marketimplied Systemic Risk.” IMF working paper, WP/13/54.

Jones, E.P., S.P. Mason and E. Rosenfeld. 1984. "Contingent Claims Analysis of Corporate Capital Structures: An Empirical Investigation.” Journal of Finance 39(3): 611-625.

Keim, D. B. and R. F. Stambaugh. 1984. "A Further Investigation of the Weekend Effect in Stock Returns.” The Journal of Finance 39(3): 819-835.

Keim, D.B. and E. B. Stambaugh. 1986. "Predicting Returns in the Stock and Bond Markets." Journal of Financial Economics 17(2): 357-390

KMV Corporation. 1999. “Modeling Default Risk.” Moody’s KMV.

Koijen, R. S. J., H. Lustig and S. V. Nieuwerburgh. 2012. "The Cross-Section and Time-Series of Stock and Bond Returns." NBER Working Paper No. 15688.

Koussis, N. and S. Martzoukos. 2012. "Investment Options with Debt-financing Constraints." The European Journal of Finance 18(7): 619-637

Kwan, S. H. 1996. "Firm-specific Information and the Correlation between Individual Stocks and Bonds." Journal of Financial Economics 40(1): 63-80.

Lee, B. S., G. Hong and Y. Kim. 2011. "Correlations between Stock Returns and Bond Returns: Income and Substitution Effects.” Quantitative Finance iFirst, 1-20. 
Lustig, H., S. V. Nieuwerburgh and A. Verdelhan. 2013. "The Wealth-Consumption Ratio," NYU Working Paper No. FIN-08-045.

Merton, R. C. 1973. “Theory of Rational Option Pricing.” Bell Journal of Economics and Management Science 4(1):141-183.

Merton, R. C. 1974. "On the Pricing of Corporate Debt: The Risk Structure of Interest Rates." Journal of Finance 29(2): 449-470.

Modigliani, F. and M. Miller. 1958. "The Cost of Capital, Corporation Finance and the Theory of Investment.” American Economic Review 48(3): 261-297.

Norden, L. and M. Weber. 2009. "The Comovement of Credit Default Swap, Bond and Stock Markets: an Empirical Analysis.”European Financial Management Journal 15(3): 529_ 562

Opler, T.C. and S. Titman. 1994. "Financial Distress and Corporate Performance.” The Journal of Finance 49(3): 1015-1040.

Shane, H. 1994. "Comovements of Low-grade Debt and Equity Returns of Highly Leveraged Firms.” The Journal of Fixed Income 3(4): 79-89.

Yang, J., Zhou, Y. and Z., Wang. 2009. "The Stock-Bond Correlation and Macroeconomic Conditions: One and a Half Centuries of Evidence.” Journal of Banking \& Finance 33(4): 670-680 


\section{Table 1}

\section{Summary statistics in Equation (4)}

The table contains summary statistics and correlations of the variables in Equation (4). $R S$ and $R B$ are the logarithm returns of stock and bond issued by the same firm, respectively. $R V$ is the logarithmic return on the value of the firm, where the estimation for the value of the firm follows Jones et al.'s (1984) method. $D \_V o l(R V)$ is the change in the volatility of $R V$, calculated as the logarithmic change of the volatility of $R V$. $R M$ is the logarithmic return of the FTSE 100 market index. $\operatorname{Vol}(R M)$ is the volatility of $R M$ over a rolling window of $(\mathrm{t}-$ 5, t). Lev1 is the ratio of the firm's market value of total debts to market value of equity in logarithmic, where the market value of total debts is estimated as the interaction of total debts and the market-to-book ratio of a longterm tradable bond of the firm. All variables are expressed in percentage.

\begin{tabular}{|c|c|c|c|c|c|c|c|}
\hline & $R S$ & $R B$ & $R V$ & $D_{-} \operatorname{Vol}(R V)$ & $R M$ & $\operatorname{Vol}(R M)$ & Lev1 \\
\hline \multicolumn{8}{|c|}{ Panel A. Summary statistics } \\
\hline Mean & -0.05 & -0.01 & -0.03 & 0.26 & 0.00 & -30.13 & -110.13 \\
\hline Std.dev. & 2.00 & 0.46 & 1.16 & 28.82 & 1.05 & 57.98 & 60.19 \\
\hline Min & -39.58 & -10.93 & -25.09 & -221.77 & -8.18 & -203.27 & -279.37 \\
\hline Max & 25.91 & 5.72 & 8.75 & 250.69 & 8.47 & 164.01 & 68.32 \\
\hline \multicolumn{8}{|c|}{ Panel B. Correlation matrix } \\
\hline$R S$ & 1.00 & & & & & & \\
\hline$R B$ & -0.07 & 1.00 & & & & & \\
\hline$R V$ & 0.87 & 0.08 & 1.00 & & & & \\
\hline$D_{-} \operatorname{Vol}(R V)$ & 0.03 & -0.04 & -0.02 & 1.00 & & & \\
\hline$R M$ & 0.44 & -0.12 & 0.38 & -0.01 & 1.00 & & \\
\hline $\operatorname{Vol}(R M)$ & -0.04 & -0.03 & -0.05 & 0.03 & -0.02 & 1.00 & \\
\hline Lev1 & 0.00 & 0.00 & -0.01 & -0.01 & 0.02 & 0.02 & 1.00 \\
\hline
\end{tabular}




\section{Table 2}

\section{Summary statistics of $D_{-} \operatorname{Vol}(R V)$ in the three examination event windows}

The table reports the summary statistics of $D_{-} \operatorname{Vol}(R V)$ in the examination event windows of $(-30,-4),(-40,-4)$ and $(-50,-4)$. D_Vol $(R V)$ is defined in Table 1 .

\begin{tabular}{lllll}
\hline Examination event windows & Mean & Std.dev. & Min & Max \\
\hline$(-30,-4)$ & 0.26 & 28.82 & -221.77 & 250.69 \\
$(-40,-4)$ & 0.08 & 29.45 & -315.07 & 289.14 \\
$(-50,-4)$ & 0.09 & 29.68 & -315.07 & 289.14 \\
\hline
\end{tabular}




\section{Table 3}

\section{Summary statistics in Equation (5)}

The table contains summary statistics and correlations of the variables in Equation (5). ROA is the return on assets. Lev2 is the ratio of total debts to total equity. Both figures are reported in firms' annual financial reports. $R S, R B$, $R M$ and $\operatorname{Vol}(R M)$ are defined in Table 1.

\begin{tabular}{|c|c|c|c|c|c|c|}
\hline & $R S$ & $R B$ & $R O A$ & Lev2 & $R M$ & $\operatorname{Vol}(R M)$ \\
\hline & \multicolumn{6}{|c|}{ Panel A. Summary statistics } \\
\hline Mean & -0.02 & 0.01 & 7.10 & 92.73 & 0.14 & -35.96 \\
\hline Std.dev. & 1.59 & 0.36 & 7.64 & 83.32 & 1.17 & 65.33 \\
\hline Min & -4.78 & -1.24 & -15.64 & 21.45 & -3.19 & -193.78 \\
\hline \multirow[t]{2}{*}{ Max } & 5.96 & 1.49 & 52.88 & 521.97 & 4.93 & 108.35 \\
\hline & \multicolumn{6}{|c|}{ Panel B. Correlation matrix } \\
\hline$R S$ & 1.00 & & & & & \\
\hline$R B$ & -0.24 & 1.00 & & & & \\
\hline$R O A$ & 0.11 & 0.24 & 1.00 & & & \\
\hline Lev2 & 0.29 & -0.04 & 0.36 & 1.00 & & \\
\hline$R M$ & 0.58 & -0.29 & -0.08 & 0.06 & 1.00 & \\
\hline $\operatorname{Vol}(R M)$ & -0.04 & -0.06 & 0.14 & 0.16 & -0.19 & 1.00 \\
\hline
\end{tabular}




\section{Table 4}

\section{Estimates of Equation (4) in various event windows}

The table reports the estimates of Equation (4) using fixed effects model in the examination event windows of ($30,-4),(-40,-4)$ and $(-50,-4)$. The dependent variable are stock returns $(R S)$ and bond returns $(R B)$, respectively. The estimated coefficients of the vector of the lagged variables $\beta(L .)^{\prime}$, which is used as control variables for the regression for $R B$, are not presented in the table for brevity but available on request. All variables are defined in Table 1 . The t-statistics are in parentheses. $* * *$ refers to the $1 \%$ significance level.

\begin{tabular}{llll}
\hline \multicolumn{1}{c}{$(-30,-4)$} & \multicolumn{2}{c}{ examination event windows } & $(-50,-4)$ \\
\hline Equation (4) with dependent variable: $R S$ & & $(-40,-4)$ & \\
\hline$R V$ & 1.25 & 1.11 & $(114.99)^{* * *}$ \\
& $(94.9)^{* * *}$ & $(93.56)^{* * *}$ & $3.75 \mathrm{E}-03$ \\
D_Vol(RV) & $2.91 \mathrm{E}-03$ & $4.26 \mathrm{E}-03$ & $(9.92)^{* * *}$ \\
& $(6.15)^{* * *}$ & $(9.4)^{* * *}$ & 0.23 \\
$R M$ & 0.21 & 0.26 & $(20.48)^{* * *}$ \\
& $(14.46)^{* * *}$ & $(19.16)^{* * *}$ & $1.02 \mathrm{E}-05$ \\
Vol(RM) & $2.00 \mathrm{E}-04$ & $3.20 \mathrm{E}-04$ & $(0.03)$ \\
& $(0.5)$ & $(0.87)$ & -0.01 \\
Lev1 & -0.02 & -0.01 & $(-3.16)^{* * *}$ \\
& $(-4.02)^{* * *}$ & $(-5.1)^{* * *}$ & -0.76 \\
$R^{2}$ & -1.75 & -1.67 & $(-3.16)^{* * *}$ \\
\hline
\end{tabular}

Equation (4) with dependent variable: $R B$

\begin{tabular}{llll}
\hline$R V$ & 0.81 & 0.77 & 0.78 \\
& $(109.40)^{* * *}$ & $(119.12)^{* * *}$ & $(139.5)^{* * *}$ \\
$D_{-}$Vol(RV) & $-3.20 \mathrm{E}-04$ & $-5.00 \mathrm{E}-05$ & $-5.42 \mathrm{E}-05$ \\
& $(-2.74)^{* * *}$ & $(-0.54)$ & $(-0.64)$ \\
$R M$ & -0.01 & $-9.40 \mathrm{E}-04$ & $-2.30 \mathrm{E}-03$ \\
Vol(RM) & $(-3.49)^{* * *}$ & $(-0.30)$ & $(-0.89)$ \\
& $3.00 \mathrm{E}-05$ & $-3.00 \mathrm{E}-05$ & $-6.25 \mathrm{E}-05$ \\
Lev1 & $(0.18)$ & $(-0.20)$ & $(-0.53)$ \\
& 0.49 & 0.48 & 0.48 \\
constant & $(113.06)^{* * *}$ & $(122.25)^{* * *}$ & $(142.48)^{* * *}$ \\
& 0.52 & 0.08 & 0.01 \\
$R^{2}$ & $(4.77)^{* * *}$ & $(1.03)$ & $(0.23)$ \\
\hline
\end{tabular}




\section{Table 5}

\section{Estimates of Equation (5)}

The table reports the estimates of Equation (5) using OLS with Huber-White robust standard errors. The dependent variables are stock returns $(R S)$ and bond returns $(R B)$, respectively. All variables are defined in Table 3 . The robust t-statistics are in parentheses. $* * *$ and $*$ refer to the $1 \%$ and $10 \%$ significance level, respectively.

\begin{tabular}{|c|c|c|c|c|c|}
\hline & $R O A$ & Lev2 & $R M$ & $\operatorname{Vol}(R M)$ & constant \\
\hline \multicolumn{6}{|c|}{ Equation (5) with dependent variable: $R S$} \\
\hline Coefficent & 0.01 & 4.29E-03 & 0.79 & 4.72E-04 & -0.62 \\
\hline t-statistic & $(1.05)$ & $(3.3)^{* * *}$ & $(6.08)^{* * *}$ & 0.28 & $(-2.89)^{* * *}$ \\
\hline $\operatorname{adj}-R^{2}$ & 0.41 & & & & \\
\hline \multicolumn{6}{|c|}{ Equation (5) with dependent variable: $R B$} \\
\hline Coefficent & 0.01 & $-4.11 \mathrm{E}-04$ & -0.09 & $-7.60 \mathrm{E}-04$ & -0.06 \\
\hline t-statistic & $(4.04)^{* * *}$ & $(-1.68)^{*}$ & $(-2.39)^{* * *}$ & $(-1.61)^{*}$ & $(-1.28)$ \\
\hline adj- $R^{2}$ & 0.16 & & & & \\
\hline
\end{tabular}

